
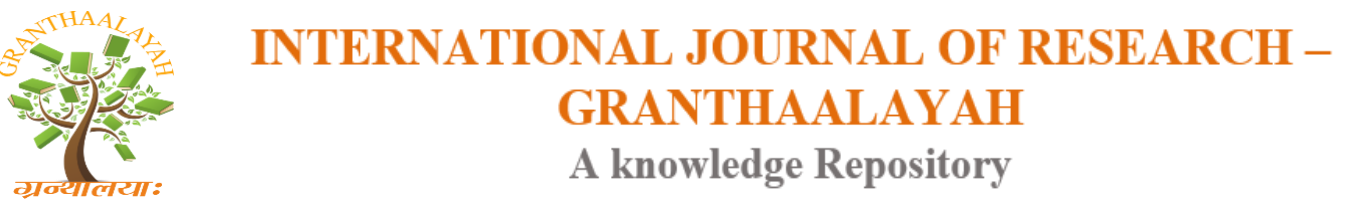

Social

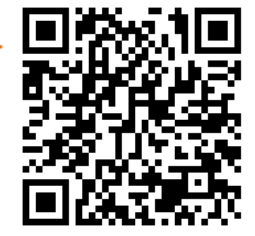

\title{
CASE STUDY OF PERSON WITH BODY DYSMORPHIC DISORDER
}

\author{
Dr. M.Senthil ${ }^{* 1}$ \\ ${ }^{* 1}$ Psychiatric Social Worker, Department of Psychiatry, Post Graduate Institute of Medical \\ Education Research, Chandigarh, INDIA
}

DOI: $10.5281 /$ zenodo.58711

\section{ABSTRACT}

This article presents a case study of client with Body dysmorphic disorder. Body dysmorphic disorder is an increasingly recognized somatoform disorder, clinically distinct from obsessivecompulsive disorder, eating disorders, and depression. Patients with body dysmorphic disorder are preoccupied with an imagined deficit in the appearance of one or more body parts, causing clinically significant stress, impairment, and dysfunction. The preoccupation is not explained by any other psychiatric disorder. Patients present to family physicians for primary care reasons and aesthetic or cosmetic procedures. Cosmetic correction of perceived physical deficits is rarely an effective treatment. Pharmacologic treatment with selective serotonin reuptake inhibitors and non-pharmacologic treatment with cognitive behavior therapy are effective. Body dysmorphic disorder is not uncommon, but is often misdiagnosed. Recognition and treatment are important because this disorder can lead to disability, depression, and suicide. Psychiatric social work assessment and intervention was provided to the person with Body dysmorphic disorder, focusing on to building for change in misbelieve and strengthening commitment to change. The psycho social intervention was provided to the patients and his family members. Sessions on Admission counseling, Family intervention, Supportive therapy, Psycho education, role play, reminiscence, Pre discharge counseling, Discharge Counseling and Social Group Work was conducted. At the end of the therapy, the client knowledge about the illness and coping skills has improved.

Keywords:

Body dysmorphic disorder, Mental illness, Family.

Cite This Article: Dr. M.Senthil, "CASE STUDY OF PERSON WITH BODY DYSMORPHIC DISORDER" International Journal of Research - Granthaalayah, Vol. 4, No. 7 (2016): 102-108.

\section{INTRODUCTION}

Italian physician Enrique Morselli first described body dysmorphic disorder (BDD) in 1891 by using the term "dysmorphophobia" defined as the fear of having a deformity (Phillips,2005 ). The American Psychiatric Association classified BDD as a distinct somatoform disorder in 1987 (APA, 2002). BDD has received particular attention in the media and in clinical research over 
the past 10 years. Patients with BDD are preoccupied with a perceived physical defect, and this disrupts their lives by causing them considerable social distress and occupational dysfunction. They may seek care for their perceived defects from many subspecialties, including dermatology (Wilson, 2004), cosmetic surgery (Sarwer, 2008), dentistry (Herren, 2003), psychiatry, and family medicine. These patients often want cosmetic and aesthetic procedures, which have become more affordable and available than ever before. Therefore, family physicians who perform in-office aesthetic procedures (e.g., botulinum toxin type A injections [Botox]; filler injections [collagen and hyaluronic acid]; mesotherapy; micro-dermabrasion) may encounter patients with BDD. However, cosmetic procedures rarely improve the symptoms of patients with BDD, and often add to their psychic distress; therefore, considering the presence of this disorder before performing aesthetic procedures has been recommended. Furthermore, numerous reports have documented patients with BDD committing violent acts toward physicians who perform procedures on them (Cotterill, 1996). Body dysmorphic disorder is characterized by a preoccupation with a minimal or nonexistent appearance defect and must cause significant distress and/or interfere with the social and work life of the patient. The perceived physical anomaly may involve the shape and size of the whole body or may be centered around single units such as the face, nose, skin, and hair. It is not confined to one region; often, patients have vague or specific complaints involving more than one body part, with the majority being bothered by three to four different areas that may shift to another over time. Insight that the concerns are excessive may vary inter individually and also change over the course of the disease, but is generally poor. Patients are deeply convinced of the severity of their defects and cannot be talked out of their belief. The onset is gradual \& consists of repetitive, time-consuming acts such as checking mirrors and hiding perceived defects with makeup, hats, and so forth, or even performing "self-surgery" in extreme cases. They tend to focus almost exclusively on their perceived defect in appearance rather than seeing the entirety of themselves. Many find glimpsing themselves in a mirror or other reflecting surface very distressing, and they avoid mirrors altogether or allow themselves to see themselves only bit by bit (eg, to apply make-up). Many can face the mirror only under certain specified and predictable conditions, for example in a darkened room and at a certain angle. Others must check themselves in the mirror repeatedly, ostensibly to reassure themselves that their appearance actually is acceptable, but mostly with the opposite effect, so that the mirror gazing merely confirms how "repulsive" they are and makes them feel even worse about themselves. BDD has been postulated to be a symptom of or related to depression. Major depression is the most common co-morbid disorder in patients with BDD. They have some noticeable differences like the presence of prominent obsessive preoccupation $\&$ repetitive compulsive behaviors in patients with BDD whereas depressed patients often focus less on their appearance, even neglecting how they look, rather than becoming over focused on it. Also BDD has a 1:1 gender ratio, earlier age of onset \& often chronic course. An area of contention is the classification of BDD. In the DSM-IV, BDD is subsumed under the somatoform disorders, but it sits uneasily there and has little in common with other members of that heterogeneous group. BDD shows substantial overlap in symptomatology with both OCD and social anxiety disorder, and arguments could be made for classifying BDD with either of those disorders. It is seen that around $50 \%$ of sufferers have a delusional form of the illness. Under DSM rules, people who have delusional BDD must be ascribed another, additional diagnostic label, namely that of delusional disorder, somatic subtype. This additional diagnosis makes little sense, because the degree of delusional conviction with which beliefs are held is considered more usefully on a spectrum rather than categorically. Available data suggest that 
delusional \& non delusional patients are similar in most respects except that delusional patients appear to have a more severe form of illness. Delusional subjects have higher levels of perceived stress \& poorer quality of life. Also, delusional \& non delusional patients have similar treatment response as in SSRI's.

\section{CLINICAL HISTORY}

$\begin{array}{ll}\text { Source of referral } & \text { : Family member } \\ \text { Sources of information } & \text { : Patient himself, pt's mother, father and Case Record File } \\ \text { Reliability and adequacy } & \text { : Reliable \& Adequate } \\ \text { Mode of admission } & \text { : Voluntarily } \\ \text { Mode of onset } & \text { : Insidious } \\ \text { Course } & \text { : Continuous } \\ \text { Progress } & \text { : Deteriorating } \\ \text { Precipitating factor } & \text { : Friends teasing him about his face and height }\end{array}$

\section{BRIEF HISTORY OF ILLNESS AND DIAGNOSIS}

Index patient 23 year old, male, single, educated up to $10^{\text {th }}$ std, Hindu religion, from middle socio economic status, rural background and nuclear family presented with the complaints of Excessive thinking about ugliness of face, Remain to be alone, and Decreased social interaction for the past 6 years. Patient was apparently alright six years back. One day his friends started to comment about his face that he has ugliness of face and also they started to tease him about his height and his body shape. Later he started to think about his face and body shape. And he started to watch the mirror frequently and measure his height frequently. By noticing about his behavior by his parents they asked him about his behavior. He explained about this and demanded to consult physician. Subsequently his interaction pattern started to decreased. He used to spend more time alone in home and he would not go out of the home. His sleep had decreased subsequently and he started to cover his face by clothes. On MSE he was unkempt and tidy, fat body build, age appropriate, uncooperative, rapport could not be established, normal psychomotor activity, soft, decreased reaction time dysphoric, appropriate and communicable affect, repeated thought, delusion of persecution impaired judgment and grade one insight.

Past history: No past history of mental illness.

Clinical Diagnosis: Body dysmorphic disorder. (According to International Classification of Disease (ICD-10)

\section{FAMILY HISTORY OF PHYSICAL AND MENTAL ILLNESS}

Index patient belongs to rural nuclear family of middle socio-economic status. Patient is the first among the four children of his parents. Patient first younger brother died by jaundice and patient third younger brother is having movement disorder. Patient fourth younger sister died still birth and there is no epilepsy, substance dependence and major medical illness in the patient family. 


\section{Family Composition:}

Father: Patient father is 50 years old, illiterate, he is doing business. $\mathrm{He}$ is strict and domineering in nature.

Mother: Patient father is 40 years old, illiterate, she is a house wife. She also loving and caring to all children and supportive to her husband in all activities.

$\mathbf{1}^{\text {st }}$ Sibling: is a patient younger brother, 18 years old and now studying in $9^{\text {th }}$ std. he is emotionally attach with the patient.

$2^{\text {nd }}$ sibling: is a younger brother, 14 years old and now studying in $7^{\text {th }}$ std. he likes the patient but not very much attachment with the patient.

\section{FAMILY DYNAMICS}

Boundaries: This family is following semi open and semi permeable. The patient family matters will allow others to such as relative, neighbors and friends to suggest about family functioning in some extent and takes only good thing and leave the bad thing which cause the family issues.

Family developmental stage: The family is in $5^{\text {th }}$ stage i.e." Families with teenagers".

Leadership pattern: Patient's father plays the role of nominal and functional head of the family. Decision-making process: patient father takes decision without consulting wife and children when it is necessary. So the patient father follows autocratic way of decision.

Role structure and functioning: In this family except patient each one has their specific role in the family which serves the purpose of the family function. Patient is not doing any work because of his illness.

Communication: There is clear and direct communications in the family. Family affairs are communicated well between the family members. Communication between family members has been healthy. But patient is using indirect communication. Patient takes mother help to communicate with father i.e. he passes the message to through mother to father.

Reinforcement: Adequate

Adaptive patterns: Problem solving ability and coping strategy found to be healthy in the family.

Social support system:

Primary: Primary support system is adequate. Patient family members are very support to him. Secondary: Secondary social support from close relatives is adequate in terms of emotional support.

Tertiary: Patient tertiary support is adequate. The family used to seek support from different health institutions.

\section{ATTITUDE OF THE FAMILY MEMBERS TOWARDS THE ILLNESS AND PATIENT}

His family members are worried about his illness. They are aware about mental illness, but they are more believing superstitious belief over the illness. Patient has shown to a faith healer and has taken treatment for two years.

Expressed Emotions:

Critical comment : Low

Hostility : High 
$\begin{array}{ll}\text { Dissatisfaction } & \text { : High } \\ \text { Over involvement } & \text { : Low } \\ \text { Warmth } & \text { : Low }\end{array}$

\section{PERSONAL HISTORY}

Birth and easily development: Patient was born out of full term normal delivery, at hospital. All millstones of development were attained at the right time.

Presence of childhood disorder: He was a normal child.

Home atmosphere in childhood: Home atmosphere was reported to be congenial.

Educational history: he started schooling at the age of 5 in Hindi medium school and currently doing nothing simply sitting in home. He was an average student in studies. His participation in extracurricular activities was reported to be unsatisfactory.

General pattern of living: Patient's family has pucca house of 5 rooms with some basic facilities.

Pre-morbid temperament:

- Social interaction: Patient's interaction with family members, friends and others was reported to be better.

- Intellectual activities: he did not carry out any intellectual activities.

- Mood: Patient was most of the time euthymic and at times anxious.

- Character: he was found to have good character.

- Attitude: he had positive attitude towards everyone at home including his parents.

- Interpersonal relationship: Patient had warm interpersonal relationship with family members, friends and others.

- Reaction patterns to stress: The patient used to get angry or irritable rarely whenever he was under stress.

- Standards: he had normal religious and moral standards but had social one.

- Habit: he had no any habit of substances.

\section{PSYCHO SOCIAL DIAGNOSIS}

- Family showing dysfunction in the areas like communication, affective responsiveness and affective involvement

- Negative expressed emotions are present in the form of hostility and dissatisfaction.

- Severe dysfunctions are presenting in all the areas like social functioning, vocational functioning, personal functioning, family functioning, and cognitive functioning.

- Patient has weak relationship with father, relatives, neighbours, religious place and friends.

- Patient father is found to be domineering and over strict.

- Patient family has more superstitious belief

- The illness has affected the patients happiness, social interaction, studies, motivation, quality of life, functioning, and behavior of the patient 


\section{PSYCHOSOCIAL MANAGEMENT PLAN}

Treatment course: with patient 10 sessions and with family 2 sessions.

Therapy package with the patient: Cognitive restructuring of cognitive distortions related to body image, Social skills training, activity scheduling, Identifying mastery and pleasurable activities of the patient based on that make the patient to engage in some activities, and Supportive psychotherapy for secondary depressive symptoms after resolution of his psychotic symptoms.

Therapy package with the Family: Psycho education, Ensure compliance with the therapist and medications, Avoid frequent doctor shopping and Follow the home work nonpharmacological intervention.

\section{THE INTERVENTION PROCESS}

Development of therapeutic relationship: Initial session was spent for developing a good rapport with the patent and it had taken few more session to establish rapport with the patient as the patient was uncooperative.

Psychoeducation to the patient: The patient was psycho-educated about the nature of the illness, course, prognosis and the need for regular treatment. Besides, he was told how recurrent relapse worsens the course and prognosis, and was given some suggestions about how to keep himself engage in some meaningful activity.

Supportive counseling: Initially patient was motivated to express his feelings and emotions and frustrations. He came out with a lot of frustration and helplessness because of persistent family troubles and illness. The therapist expressed empathy and appropriate response to his feelings where it was required. After this ventilation, the patient was supported by giving his reassurance that he would certainly come out of problem and that his family members and we professionals were there to help him out. Therapist assists him to understand his positives and negatives and the faulty behaviors which he has and motivated to avoid such behaviors in future.

Family counseling: Initially they were well explained about the illness, nature of illness, importance of regular medication, need of primary support and early signs of relapse. Besides, that emphasis made on the family dysfunctions which were found in the family assessments were shared with them and motivated to clear such things in their family. They were explained about the open and clear communication, open boundary, democratic leadership, strong cohesiveness, adequate reinforcement and healthy adaptive patterns for enhance the family functioning and for relapse prevention.

Pre-discharge counseling: In the session both patient and his family members were involved and educated about medication side effects, follow up and early signs of relapse. They were told what they should do when patient either has side effects or shows early signs of relapse or develops poor compliance. It was also emphasized that patient ought to be engaged in some productive activities which would help him maintain physically, psychologically and socially fit.

\section{CONCLUSION}

Patient had gained insight regarding his illness. Family members have better understanding about patient's illness. Thus it can be said that Psycho-social interventions play an important role in determination of treatment outcomes. It has been shown to improve patient compliance to 
medication and the retention of patients in treatment. Psychiatric social work can play a key role in working with person with body dysmorphic disorder, educating, teaching social skills and also working with the family. So we can conclude that treatment and rehabilitation of patients with body dysmorphic disorder has been an important area of psychiatric social work. Psychosocial intervention can enhance pharmacological treatment efficacy by increasing medication compliance, maintenance in treatment, and attainment of skills.

\section{REFERENCES}

[1] Feeling Good About the Way You Look: A Program for Overcoming Body Dysmorphic Disorder, by Sabine Wilhelm, PhD (Guilford Press, 2006)

[2] The Broken Mirror: Understanding and Treating Body Dysmorphic Disorder, by Katharine Phillips, MD (Oxford University Press, 2005)

[3] Understanding Body Dysmorphic Disorder, by Katharine Phillips, MD (Oxford University Press, 2009)

[4] Phillips KA. The Broken Mirror: Understanding and Treating Body Dysmorphic Disorder. New York, NY: Oxford University Press; 2005.

[5] American Psychiatric Association. Diagnostic and Statistical Manual of Mental Disorders. 4th ed. Washington, DC: American Psychiatric Association; 2002:510.

[6] Wilson JB, Arpey CJ. Body dysmorphic disorder: suggestions for detection and treatment in a surgical dermatology practice. Dermatol Surg. 2004;30(11):1391-1399.

[7] Sarwer DB, Whitaker LA, Pertschuk MJ, Wadden TA. Body image concerns of reconstructive surgery patients: an underrecognized problem. Ann Plast Surg. 1998;40(4):403-407.

[8] Herren C, Armentrout T, Higgins M. Body dysmorphic disorder: diagnosis and treatment. Gen Dent. 2003;51(2):164-166.

[9] Cotterill JA. Body dysmorphic disorder. Dermatologic Clinic. 1996;14(3):457-463. 